\title{
ÍNDICE MEIÓTICO E VIABILIDADE POLÍNICA DE Hymenaea courbaril L., NO MUNICÍPIO DE ALTA FLORESTA, MATO GROSSO, BRASIL
}

Taynara Antunes dos Santos ${ }^{1}$, Auana Vicente Tiago ${ }^{2}$, Edimilson Leonardo Ferreira ${ }^{3}$, Alex Souza Rodrigues ${ }^{4}$, Ana Aparecida Bandini Rossi ${ }^{5}$

1. Bióloga, Universidade do Estado de Mato Grosso, Campus de Alta Floresta, MT, Brasil.

2. Doutoranda em Biodiversidade e Biotecnologia da Amazônia Legal PPGBionorte, Universidade do Estado de Mato Grosso, Campus de Alta

Floresta, MT, Brasil.

3. Graduando em Bacharelado e Licenciatura em Ciência Biológicas, Universidade do Estado de Mato Grosso, Campus de Alta Floresta, MT,

Brasil. E-mail: edimilson_bio@outlook.com

4. Mestrando em Genética e Melhoramento de Plantas da Universidade Estadual do Norte Fluminense, Darcy Ribeiro (UENF), Campos dos Goytacazes-RJ, Brasil.

5. Professora adjunta da Faculdade de Ciências Biológicas e Agrárias, Universidade do Estado de Mato Grosso, Campus de Alta Floresta, MT, Brasil.

Recebido em: 06/04/2019 - Aprovado em: 10/06/2019 - Publicado em: 30/06/2019 DOI: 10.18677/EnciBio_2019A146

\begin{abstract}
RESUMO
Hymenaea courbaril L. (Fabaceae), conhecida como jatobá, é uma espécie de porte arbóreo que possui distribuição geográfica entre as regiões tropicais, podendo atingir uma altura de 40 metros. O estudo teve como objetivo analisar o índice meiótico (IM) e viabilidade polínica (VP) de $H$. courbaril, visando fornecer subsídios para futuros programas de conservação da espécie. Foram amostrados indivíduos de duas populações, população rural (PR) e população urbana (PU), do município de Alta Floresta, MT. Utilizaram-se botões florais na fase de pré-antese e antese. Para análise do IM foram preparadas seis lâminas para cada população, sendo contabilizadas 250 células por lâmina. Na análise da VP, para cada corante, carmim acético $2 \%$, lugol, sudan IV e reativo de Alexander, foram preparadas 10 lâminas, contabilizando 500 grãos de pólen/lâmina. Os indivíduos da PR apresentaram um número maior de tétrades (1160). Nas duas populações foram encontradas células anormais, porém na PU o número foi maior, apresentando mônades (2) e tríades (419). O índice meiótico para PR foi de 77,33\% e PU de 71,93\%. Os testes colorimétricos utilizados foram capazes de distinguir os polens viáveis dos inviáveis, obtendo-se resultados satisfatórios para PR, destacando o corante sudan IV, com $95,60 \%$ de viabilidade. Já na PU o reativo de Alexander foi quem se destacou com $71,48 \%$ de viabilidade. A espécie Hymenaea courbaril apresenta irregularidades meióticas para ambas as localidades estudadas, com menor média para a ENCICLOPÉDIA BIOSFERA, Centro Científico Conhecer - Goiânia, v.16 n.29; p. 1890 2019
\end{abstract}


população urbana, que consequentemente também demonstrou uma baixa viabilidade para os grãos de pólen.

PALAVRAS-CHAVE: Corantes, grãos de pólen, jatobá.

\title{
MEYOTIC INDEX AND POLYNICAL VIABILITY OF Hymenaea courbaril L., IN THE ALTA FLORESTA MUNICIPALITY, MATO GROSSO, BRAZIL
}

\begin{abstract}
Hymenaea courbaril L. (Fabaceae), known as jatobá, is a tree species that has a geographical distribution between tropical regions, reaching a height of 40 meters. The objective of this study was to analyze the meiotic index (IM) and pollen viability (VP) of $H$. courbaril, aiming to provide subsidies for future conservation programs of the species. We sampled individuals from two populations, rural population (PR) and urban population (PU), from the city of Alta Floresta, Mato Grosso State. Flower buds were used in the pre-anthesis and anthesis phases. For IM analysis, six slides were prepared for each population, counting 250 cells per blade. In the PV analysis, 10 slides were prepared for each dye, acetic carmine $2 \%$, lugol, sudan IV and Alexander reagent, counting 500 pollen / blade grains. PR individuals had a higher number of tetrads (1160). In both populations, abnormal cells were found, but in PU the number was higher, presenting monads (2) and triads (419). The meiotic index for PR was $77.33 \%$ and for PU 71.93\%. The colorimetric tests were able to distinguish the viable pollen from the non-viable pollen, obtaining satisfactory results for PR population. In PR population we highlight the dye sudan IV with $95.60 \%$ of viability and for the PU population, we stand out Alexander reacted with $71.48 \%$ of viability. The species Hymenaea courbaril presents meiotic irregularities for both studied localities, with a lower average for the urban population, which consequently also showed a low viability for the pollen grains.
\end{abstract}

KEYWORDS: Dyes, pollen grains, Jatobá.

\section{INTRODUÇÃO}

Hymenaea courbaril L. (Fabaceae), conhecida como jatobá é uma espécie monoica, com flores monóclinas e reprodução sexuada, polinizada por morcegos; possui porte arbóreo, podendo atingir uma altura de 40 metros (FLORA DO BRASIL 2020, em construção). Possui distribuição geográfica entre as regiões tropicais, ocorrendo do litoral sul do Brasil até a costa ocidental da região central do México (MELLO et al., 2017).

A espécie apresenta potencial ecológico, medicinal e econômico. No setor florestal, a madeira é o produto mais comercializado, sendo utilizada na construção civil e em marcenarias (SILVA et al., 2016). A polpa do fruto, além de ser apreciada pela fauna, é utilizada pelos humanos para fabricação de farinha (LORENZI, 2002).

Apesar da sua ampla utilização, $H$. courbaril $L$ vem sofrendo com os processos de fragmentação de seus habitats, ocasionando a redução de indivíduos e levando a perda da variabilidade genética da espécie.

Deste modo, os estudos meióticos visam auxiliar no alcance de informações a respeito da reprodução das espécies e se são capazes de gerar uma progênie (CAETANO et al., 2003). Além de contribuir nos mecanismos de hereditariedade, a variabilidade genética permite observar aberrações estruturais e numéricas, provenientes de anormalidades que ocorrem durante a pré-meiose, meiose e pós- 
meiose, o que pode acarretar em uma fertilização limitada do gameta masculino (LOVE, 1949).

A analise da VP pode ser realizada com base em parâmetros citológicos, como a reação por corantes químicos (PAGLIARINI; POZZOBON, 2004). Dentre os testes colorimétricos, destacam-se os testes com lugol, carmim acético, reativo de Alexander e o sudan IV, que tem sido utilizados por vários estudos na literatura (TIAGO et al., 2014; MEIRELES, 2015; BRAMBATTI et al., 2016; RAMOS, 2017; OLIVEIRA; PIERRE, 2018).

Considerando que a espécie $H$. courbaril possui potencial econômico e medicinal, as informações sobre a VP e IM são fundamentais para estudos de ecologia, taxonomia e biologia reprodutiva. Portanto, este estudo teve o objetivo de analisar o IM e o VP de $H$. courbaril L. (jatobá), visando fornecer subsídios para futuros programas de conservação da espécie.

\section{Localização e coleta do material vegetal}

\section{MATERIAL E METODOS}

Foram amostrados indivíduos de $H$. courbaril de duas populações, localizadas na zona rural, (população rural - PR) e zona urbana, (população urbana - PU) do município de Alta Floresta, MT. As áreas de estudo estão situadas entre as coordenadas $9^{\circ} 58^{\prime} 26.1^{\prime \prime}$ S e $56^{\circ} 06^{\prime} 25.9^{\prime \prime} \mathrm{W}$ (PR) e $9^{\circ} 52^{\prime} 44.9^{\prime \prime} \mathrm{S}$ e $56^{\circ} 05^{\prime} 08.4^{\prime \prime} \mathrm{W}$ (PU).
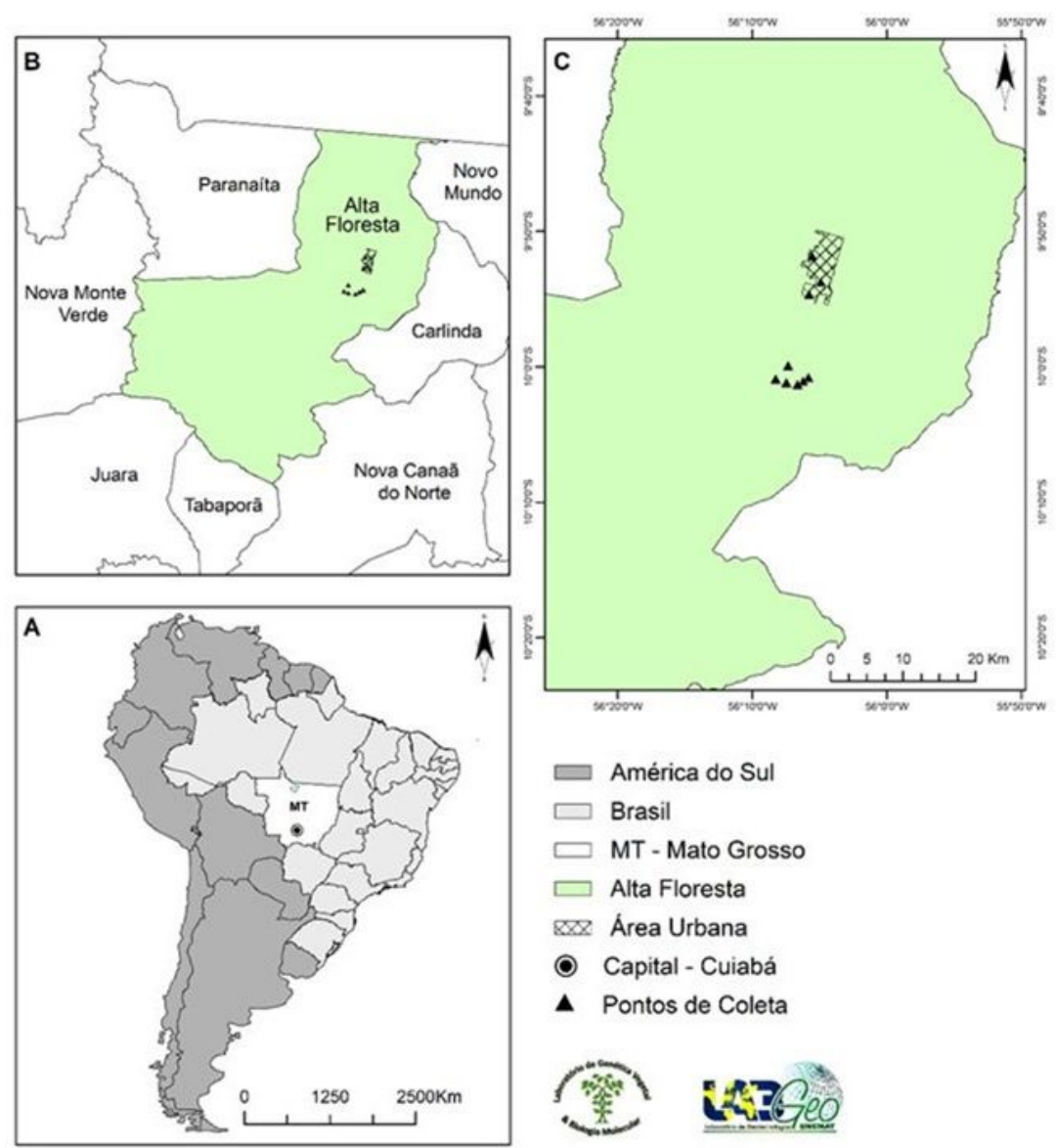

FIGURA 1. Localização geográfica dos pontos de coleta de Hymenaea courbaril nas populações rural (PR) e urbana (PU) do municipio de Alta Floresta, MT. 
Para cada população, utilizou-se um Bulk com botões florais em pré-antese e antese, oriundos de seis indivíduos para população rural e três indivíduos para população urbana. O material vegetal foi transportado para o Laboratório de Genética Vegetal e Biologia Molecular do Campus de Alta Floresta/MT - UNEMAT.

Botões florais em diversos tamanhos e diferentes estágios de desenvolvimento foram coletados e fixados em solução de etanol: ácido acético na proporção de 3:1, após um período de 24 horas. Posteriormente, a solução fixadora foi substituída por uma solução de etanol $70 \%$ e os botões florais conservados em geladeira até serem utilizados.

\section{Índice Meiótico (IM)}

Para análise do IM foram preparadas seis lâminas/população, sendo contabilizadas 250 células/lâmina, totalizando 1.500 produtos pós-meiótico por população.

A extração das anteras dos botões florais foi realizada com auxílio de pinças, em seguida as mesmas foram imersas por cinco minutos em água, dez minutos em $\mathrm{HCl} 1 \mathrm{~N}$, para facilitar a abertura das anteras e novamente em água por cinco minutos. Posteriormente, foram esmagadas em $10 \mu \mathrm{L}$ de carmim acético a $2 \%$, retirando-se o debris e recobertas com lamínulas, sendo observadas em microscopia óptica em magnitude de 400X.

O IM foi contabilizado pelo número de produtos pós-meióticos, considerando normais, os tétrades, e anormais quaisquer desvios como: mônades, díades, tríades e políades. A determinação do IM foi através da expressão recomendada por Love (1949), onde:

$$
\begin{aligned}
& \mathrm{IM}=[\text { (número total de tétrades normais/ número total de mônade + } \\
& \text { díades }+ \text { tríades }+ \text { tétrades }+ \text { políade })] \times 100 .
\end{aligned}
$$

\section{Viabilidade Polínica (VP)}

As anteras foram colocadas em lâminas e coradas com os seguintes corantes: carmim acético $2 \%$, lugol, sudan IV e reativo de Alexander. Foram preparadas 10 lâminas por corante, contabilizando 500 grãos de polens/lâmina, resultando em 10.000 grãos de pólen/corante por população. Em seguida as lâminas foram observadas em microscópio óptico na magnitude de 100X.

Os dados da VP foram transformados em arc sen $\sqrt{ } \mathrm{x} / 100$ e as médias submetidas a teste de normalidade (Lilliefors) e em seguida a análise de variância (ANOVA), sendo as médias dos corantes por população, comparadas pelo teste de Tukey a 5\% de significância, com auxílio do programa estatístico Genes (CRUZ, 2016).

\section{RESULTADOS E DISCUSSÃO}

Os indivíduos da população rural (PR) apresentaram um número maior de tétrades (Tabela 1 e Figura $2 \mathrm{C}$ ) e, consequentemente, um IM maior em relação aos indivíduos amostrados na população urbana (PU) (Tabela 1).

Love (1949) afirma que plantas que apresentam índices meióticos superiores a $90 \%$ podem ser consideradas citologicamente estáveis, o que não ocorreu com as populações de $H$. courbaril em estudo. Nas duas populações foram encontradas células anormais (Figura 2A e B), porém na PU o número foi maior, apresentando mônades e tríades (Tabela 1). 
A variação do IM entre as duas populações pode ser consequência dos diferentes ambientes nos quais os indivíduos são encontrados, como já relatado por Souza et al. (2014).

TABELA 1. Números de produtos pós-meiótico normais (tétrades) e anormais (mônades e tríade), e porcentagem do IM em duas populações de Hymenaea courbaril.

\begin{tabular}{ccccc}
\hline Populações & Mônades & Tríades & Tétrades & IM (\%) \\
\hline Rural & 0 & 340 & 1160 & 77,33 \\
Urbana & 2 & 419 & 1079 & 71,93 \\
\hline Total & 2 & 759 & 2,239 & 74,63 \\
\hline
\end{tabular}

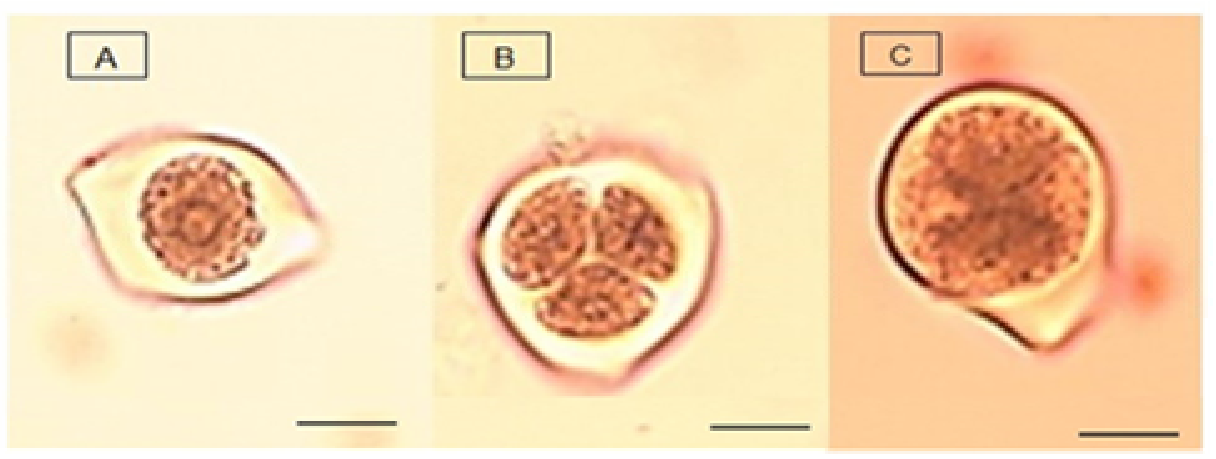

FIGURA 2. Produtos pós-meiótico. (A) Mônades; (B) Triades; (C) Tétrades em Hymenaea courbaril indentificados atraves de coloração com carmim acético $2 \%$. Barra: $14 \mu \mathrm{m}$.

Braga et al. (2018) investigando a regularidade meiótica em genótipos de Averrhoa carambola L., encontraram uma regularidade meiótica com média entre 84,96\% e 97,35\%. Lima et al., (2018) encontraram em Apeiba tibourbou 94\% de regularidade meiótica.

A estabilidade meiótica e a geração de gametas viáveis são aspectos diretamente associados à reprodução e manutenção das plantas através de sementes. A identificação de indivíduos mais estáveis mediante análise citológica permite uma seleção e um planejamento para coleta de sementes, auxiliando na eventual utilização para geração de mudas e implantação de novas populações.

Diegues (2015) relata que estudos de estabilidade meiótica e VP permitem indicar o potencial de cruzamento da planta, sendo possível obter correlações com anormalidades meióticas, auxiliar na seleção de materiais genéticos e fazer inferências sobre a eficiência de cruzamentos. Os testes colorimétricos utilizados na análise da VP de $H$. courbaril foram eficientes em distinguir os polens viáveis dos inviáveis (Figura 3). 


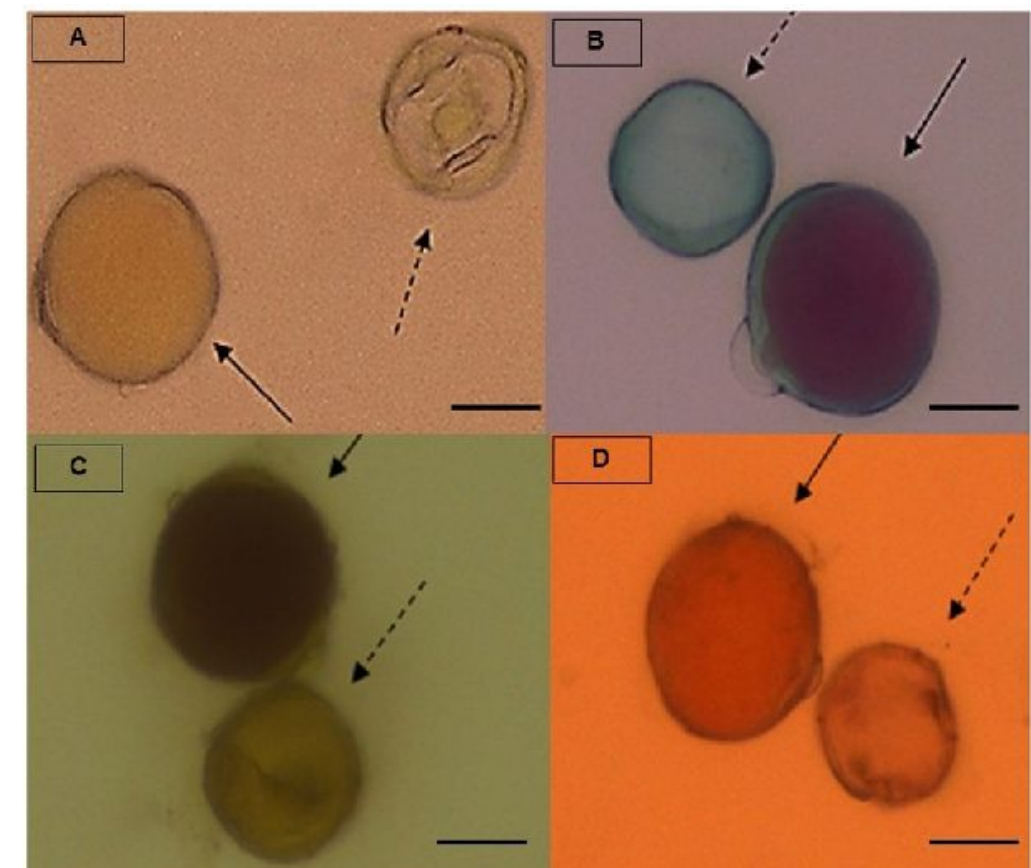

FIGURA 3. Pólen viável (seta inteira) e inviável (seta pontilhada) de Hymenaea courbaril, avaliados com os corantes: (A) Carmim Acetico 2\%; (B) Reativo de Alexander; (C) Lugol; (D) Sudan IV. Barra: $14 \mu \mathrm{m}$.

Os grãos de pólen corados com carmim acético $2 \%$ apresentam coloração avermelhada por conta da reação do corante com o material genético presente no citoplasma, já os inviáveis se mostram transparentes (Figura 3A) (PAGLIARINI; POZZOBON, 2004).

Nas lâminas coradas com o corante lugol, os grãos de pólen viáveis apresentaram-se com uma coloração marrom escuro, devido à reação química entre as moléculas de iodo e o amido presente no grão de pólen, já os inviáveis apresentaram coloração amarela devido à falta de amido (PAGLIARINI; POZZOBON, 2004). Sendo assim, os grãos de polens da espécie H. courbaril possuem amido como material nutritivo de reserva (Figura 3C).

A espécie $H$. courbaril também apresentou lipídios como substância de reserva, pois os grãos de pólen corados com o corante sudan IV apresentaram coloração vermelha (Figura 3D), conforme descrito por Baker e Baker, 1979.

Segundo Alexander (1980), através dos testes com o reativo de Alexander é possível diferenciar os grãos de pólen viáveis dos inviáveis, devido à presença do protoplasma no grão de pólen viável com corante púrpura, e para o inviável, devido à ausência de protoplasma, apresenta coloração esverdeado (Figura 3B).

Todos os corantes utilizados para a população da zona rural (PR) apresentaram resultados satisfatórios, sendo a viabilidade, maior que $90 \%$, destacando o corante sudan IV com 95,60\%. Já para população urbana, os corantes carmim acético $2 \%$, lugol, e sudan IV apresentaram resultados inferiores aos considerados satisfatórios, enquanto apenas o reativo de Alexander apresentou média de $70 \%$ (Tabela 2). Para Souza (2002), os valores de VP acima de $70 \%$ são considerados satisfatório, entre 31 a $69 \%$ como medianos e até $30 \%$ não satisfatórios. 
TABELA 2. Médias percentuais da VP em duas populações de Hymenaea courbaril por meio de quatro diferentes corantes.

\begin{tabular}{ccccc}
\hline \multirow{2}{*}{ População } & \multicolumn{4}{c}{ Corantes } \\
\cline { 2 - 5 } & Carmim Acético $2 \%$ & Lugol & Sudan IV & Reativo de Alexander \\
\hline Rural & $92,46 \mathrm{Aa}$ & $92,16 \mathrm{Aa}$ & $95,60 \mathrm{Aa}$ & $90,08 \mathrm{Aa}$ \\
Urbana & $44,22 \mathrm{Bb}$ & $43,00 \mathrm{Bb}$ & $49,86 \mathrm{Bb}$ & $71,48 \mathrm{Ab}$
\end{tabular}

Médias seguidas pelas mesmas letras maiúscula na horizontal e minúscula na vertical não apresentam diferença entre si pelo teste de Tukey a $5 \%$ de probabilidade.

Os baixos índices de viabilidade apresentados pela PU podem estar relacionados às condições atmosféricas do ambiente em que a população está inserida. Áreas urbanas estão mais sujeitas a poluentes, devido ao intenso trafego de veículos, esperando-se que os efeitos abióticos sejam mais drásticos neste ambiente, interferindo diretamente nas condições ambientais como temperatura, umidade, salinidade e déficit hídrico (ADLER; TANNER, 2015).

Xiong e Peng (2001) relatam que os grãos de pólen são altamente sensíveis aos resíduos poluentes atmosféricos. Sun et al. (2004) também relata que condições de estresses abióticos são conhecidos por prejudicar a meiose e a VP. Essas modificações poder ser capazes de eliminar ou invizibilizar a persistência da biodiversidade de espécies (PIMM et al, 2014). Como o jatobá é uma espécie ameaçada de extinção, tais fatores podem afetar o mecanismo reprodutivo colaborando para o desaparecimento da espécie.

Analisando a VP independente das populações estudadas, observa-se que não há divergência estatística entre as médias dos corantes (Figura 4), porém a maior média foi para o reativo de Alexander $(80,78 \%)$, seguido dos corantes sudan IV $(72,73 \%)$, carmim acético $2 \%(68,34 \%)$ e lugol $(67,58 \%)$.

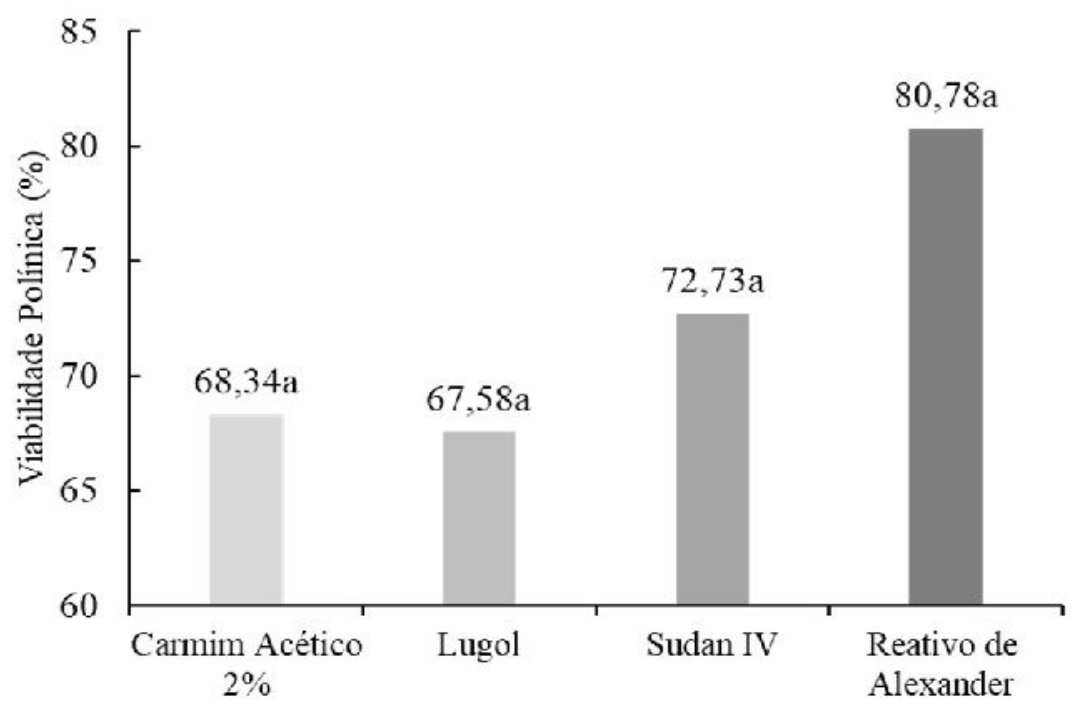

FIGURA 4. Comparação da VP de Hymenaea courbaril, entre os corantes, independente das populações. 
Hister e Tedesco (2016) relatam que o reativo de Alexander tem se mostrado superior a outros corantes, por revelar com acuricidade a VP e distinguir melhor os grãos de pólen viáveis e inviáveis, o que pode ser confirmado neste estudo, indicando seu uso em futuras avaliações com a espécie.

\section{CONCLUSÃO}

A espécie Hymenaea courbaril apresenta irregularidades meióticas para ambas as localidades estudadas, com menor média para a população urbana, que consequentemente também demonstrou uma baixa viabilidade para os grãos de pólen. Estes resultados podem ser decorrentes do processo de fragmentação dos habitats, tal como o caso da população urbana, onde os indivíduos encontram-se isolados, sofrendo maiores pressões ambientais. Isto reforça a necessidade de estratégias de conservação e manejo da espécie nas áreas estudadas.

\section{REFERÊNCIAS}

ADLER, F. R.; TANNER, C. J. Ecossistemas urbanos: princípios ecológicos para o ambiente construído. São Paulo: Oficina de Textos, 2015. 342 p.

ALEXANDER, M. P. A. Versatile stain for pollen, fungi, yeast and bacteria. Stain Technology, v. 55, n. 1, p. 13-18, 1980. Disponível em: <https://doi.org/10.3109/10520298009067890>. doi: 10.3109/10520298009067890

BAKER, H. G.; BAKER, I. Starch in angiosperm pollen grains and its evolutionary significance. American Journal of Botany, v. 66, n. 5, p. 591-600, 1979. Disponível em: <https://www.jstor.org/stable/2442509>.

BRAGA, C. S.; ZANETTI, G. T.; LIMA, J. S.; OLIVEIRA, C. A.; KARSBURG, I. V. Comportamento meiótico e viabilidade polínica de Averrhoa carambola I. (oxalidaceae) por meio de testes colorimétricos. Agrarian Academy, v. 5, n. 9, p. 478, $2018 . \quad$ Disponível em: <http://www.conhecer.org.br/Agrarian\%20Academy/2018a/comportamento\%20meioti co.pdf>. doi: 10.18677/Agrarian_Academy_2018a47

BRAMBATTI, A.; BRAMMER, S. P.; WIETHÖLTER, P.; JUNIOR, A. N. Estabilidade genética em triticale estimada pela viabilidade polínica. Instituto Biológico, v. 83, p. 01-07, 2016. Disponível em: <http://dx.doi.org/10.1590/1808-1657000802014>. doi: $10.1590 / 1808-1657000802014$

CAETANO, C. M., D’EECKENBRUJGGE, G. C., OlAYA, C. A., JIMENEZ, D. R., VEGA, J. Spindle absence in Vasconcellea cundinamarcensis (Caricaceae). Nucleus, v. 46, n. 3, p. 86-89, 2003. Disponível em: $<$ https://www.researchgate.net/publication/267511133_Spindle_absence_in_Vascon cellea_cundinamarcencis_Caricaceae>. 
CRUZ, C. D. Genes Software - extended and integrated with the R, Matlab and Selegen. Acta Scientiarum. Agronomy, v. 38, n. 4, p. 547-552, 2016. Disponível em: <http://www.scielo.br/pdf/asagr/v38n4/1807-8621-asagr-38-04-00547.pdf>. doi: 10.4025/actasciagron.v38i4.32629

DIEGUES, I. P.; JUNIOR-DAMASCENO, P. C.; RIBEIRO, N. V. S.; REIS, M. V. M.; ABBOUD, A. C. S. Comportamento meiótico e viabilidade polínica na espécie Jatropha curcas L. Semina: Ciências Agrárias, v. 36, n. 1, p. 141-150, 2015. Disponível em: $<$ http://www.uel.br/revistas/uel/index.php/semagrarias/article/view/14926/16036>. doi: 10.5433/1679-0359

FLORA DO BRASIL 2020, em construção. Jardim Botânico do Rio de Janeiro. Disponível em: <http://floradobrasil.jbrj.gov.br/>. Acesso em: 04 mar. 2019.

HISTER, C. A. L.; TEDESCO, S. B. Estimativa da viabilidade polínica de araçazeiro (Psidium cattleianum Sabine) através de distintos métodos de coloração. Revista brasileira de plantas medicinais. v. 18, n. 1, p. 135-141, 2016. Disponível em: <http://dx.doi.org/10.1590/1983-084X/15_081>.doi: 10.1590/1983-084X/15_081

JOSHI, P. C.; A. SWAMI A. Physiological responses of some tree species under roadside automobile pollution stress around city of Haridwar, India. Environmentalist, v. 27, n. 3, p. 365-374, 2007. Disponível em: <https://doi.org/10.1007/s10669-007-9049-0>. doi: 10.1007/s10669-007-9049-0

LIMA, B. F. S.; HERRMANN, F.; PARISOTTO, D. C.; NASCIMENTO, L. S. D.; KARSBURG, I. V. Índice meiótico e viabilidade polínica de Apeiba tibourbou Aubl. Agrarian Academy, v. 5, n. 9, p. 275, 2018. Disponível em: <http://www.conhecer.org.br/Agrarian\%20Academy/2018a/indice\%20meiotico.pdf>. doi: 10.18677/Agrarian_Academy_2018a27

LORENZI, H.; MATOS, F. J. A. Plantas medicinais no Brasil: nativas e exóticas cultivadas. Nova Odessa: Instituto Plantarum, 2002. 512 p.

LOVE, R. M. Estudos citológicos preliminares de trigos rio-grandenses. Porto Alegre: Secretaria do Estado dos Negócios da Agricultura, Indústria e Comércio, 1949. $23 \mathrm{p}$.

MEIRELES, A. C.; QUEIROZ, J. A.; QUIRINO, Z. G. M. Mecanismo explosivo de polinização em Periandra mediterranea (Vell.) Taub. (Fabaceae) na Reserva Biológica Guaribas, Paraíba, Brasil. Biotemas, v. 28, n. 4, p. 71-81, 2015. Disponível em: $\quad<h t t p s: / / p e r i o d i c o s . u f s c . b r / i n d e x . p h p / b i o t e m a s / a r t i c l e / v i e w / 2175-$ 7925.2015v28n4p71/31316>. doi: doi.org/10.5007/2175-7925.2015v28n4p71

MELLO, A. H.; NASCIMENTO, S. F.; OLIVEIRA, G. F. Avaliação do desenvolvimento e dependência micorrízica do jatobá (Hymenaea courbaril L.). Enciclopédia Biosfera, v. $14 \quad$ n. $25 \quad$ p. 244, 2017. Disponível em: <http://www.conhecer.org.br/enciclop/2017a/agrar/avaliacao\%20jatoba.pdf>. doi: 10.18677/EnciBio_2017A23 
OLIVEIRA, L. B. P.; PIERRE, P. M. O. Índice meiótico e palinologia de cerejeira-domato (Eugenia involucrata DC-Myrtaceae). Revista de Ciências Agroveterinárias, v. $17, \quad$ n. 4 , p. 481-490, 2018. Disponível em: <http://revistas.udesc.br/index.php/agroveterinaria/article/view/11123/pdf>. doi: $10.5965 / 223811711732018481$

PAGLIARINI, M. S., POZZOBON, M. T. II Curso de citogenética aplicada a recursos genéticos vegetais. Brasília: Embrapa Recursos Genéticos e Biotecnologia. 2004. 89 p. (documentos 154). Disponível em: $<$ https://www.infoteca.cnptia.embrapa.br/infoteca/bitstream/doc/186933/1/doc154.pdf $>$.

PIMM, S.L.; JEKINS, C.N.; ABELL, R.; BROOKS, TM. GITLEMANN, J.L.; et al.,The biodiversity of species and their rates of extinction, distribution, and protection. Science, v. 344, n. 6187, p. 987-999, 2014. Disponível em: <http://science.sciencemag.org/content/344/6187/1246752/tab-pdf>. $10.1126 /$ science. 1246752

RAMOS, L. P. N. R.; ANDRÉ, V. L. S.; MELLO, V. S.; DAMASIO, J. F.; KARSBURG, I. V. Estudo da viabilidade polínica de Myrciaria cauliflora (mart.) o. berg. por meio de distintos métodos de coloração. Agrarian academy, v. 4, n. 8, p. 143, 2017. Disponível em: <http://www.conhecer.org.br/Agrarian\%20Academy/2017b/estudo\%20da\%20viabilid ade.pdf>. doi: 10.18677/Agrarian_Academy_2017b15

SILVA, C. P.; SOUSA, M. S. B; SIGUEMOTO, E. S.; SOARES, R. A. M.; ARÊAS, J. A. G. Chemical composition and antioxidant activity of jatobá-do-cerrado (Hymenaea stigonocarpa Mart.) flour. Food Science and Technology, v. 34, n. 3, p. 597-603, 2014. Disponível em: <http://www.scielo.br/pdf/cta/v34n3/24.pdf>. doi: dx.doi.org/10.1590/1678-457X.6405

SILVA, S. M. M.; WADT, L. H. O.; MESQUITA, A. G. G.; MARTINS, K. Impacto da exploração madeireira na diversidade genética e área basal de jatobá na Amazônia sul-ocidental. Scientia Forestalis, v. 44, n. 111, p. 545-555, 2016. Disponível em: <https://www.ipef.br/publicacoes/scientia/nr111/cap01.pdf>. dx.doi.org/10.18671/scifor.v44n111.01

SOUZA, M. M.; PEREIRA, T. N. S.; VIANA, A. P.; PEREIRA, M. G.; BERNACCI, L. C.; SUDRÉ, C. P.; SILVA, L. C. Meiotic irregularities and pollen viability in Passiflora edmundoi Sacco (Passifloraceae). Caryologia, v. 56, n. 2, p. 161-169, 2014. Disponível em: <https://doi.org/10.1080/00087114.2003.1010589320>. doi: $10.1080 / 00087114.2003 .1010589320$

SUN, M.; GROSS, K.; SCHIESTL, F. P. Floral adaptation to local pollinator guilds in a terrestrial orchid. Annals of Botany, v. 113, n. 2, p. 289-300, 2014. Disponível em: <https://doi.org/10.1093/aob/mct219>. doi: 10.1093/aob/mct219 
TIAGO, A. V.; ROCHA, V. D; TIAGO, P. V.; LIMA, J. S.; ROSSI, A. A. B. Viabilidade polínica e receptividade estigmática em variedades de mandioca (Manihot esculenta Crantz). Enciclopédia Biosfera, v. 10, n. 19, p. 1957, 2014. Disponível em: <http://www.conhecer.org.br/enciclop/2014b/AGRARIAS/Viabilidade\%20Polinica.pdf

XIONG, Z. T; PENG, Y. H. Response of pollen germination and tube growth to cadmium with special reference to low concentration exposure. Ecotoxicology and Environmental Safety, v. 48, n. 1, p. 51-55, 2001. Disponível em: <https://doi.org/10.1006/eesa.2000.2002>. doi: 10.1006 / eesa.2000.2002 